\title{
Table of statutory materials
}

Agreement on the transfer and mutualisation of contributions to the Single Resolution Fund 2014 (SRF IGA)..........................139, 142-145, 172

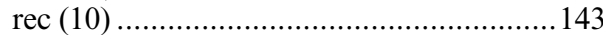

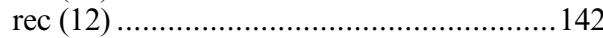
Art 1(1)(b) .............................................. 140

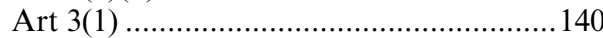
Art 3(2) .................................................. 140

Art 3(3) .................................................. 140

Art 4(1) ................................................ 140

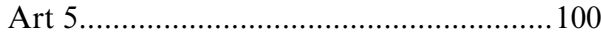

Art 5(1)(a) ................................................ 140

Art 5(1)(b) .......................................... 140

Art 5(1)(c) .............................................. 141

Art 5(1)(d) .......................................... 141

Art 5(1)(3) ............................................. 141

Art 11(2) ....................................... 140, 142

Art 12(4) ................................................ 172

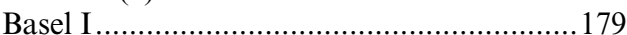

Basel II accord 2004........... 175, 177, 179, 232, 463,568

Basel III accord (2010)......... 9, 34, 85, 88, 175, $177-179,180,182,186,187,188,189$, 190, 191, 192, 194, 196, 197, 198, 199, 200, 201, 202, 203, 205, 206, 207, 208, $209,210,213,230,232,233,234,427$, $443,444,516$

Charter of Fundamental Rights of the

European Union ........................ 381, 489

Art 17 $379,380,391,393$

Art 42(1)(c) 138

Art 51 391

Art 51(1) ..380

Art 52(3) 380,393

Core Principles for Effective Deposit Insurance Systems (Basel Committee on Banking Supervision (BCBS)/ International Association of Deposit Insurers (IADI)) .......................... 351, 352 Pr 2 351,352

European Convention on Human Rights $129,380,399$

Art 6. 390

Art 1 of the First Protocol ............. 379, 380, 381-388, 390, 393, 394, 396, 398, 527, 536 European Stability Mechanism (ESM) Treaty, 2012 $154,164,167$

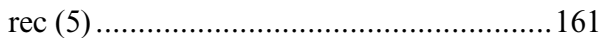

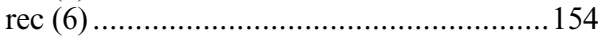

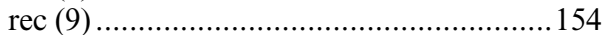

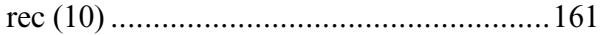

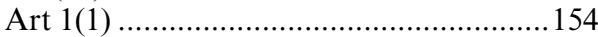

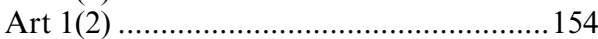

Art 2(1) ................................................ 154

Art 3 3....................................... 154, 166

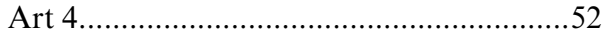

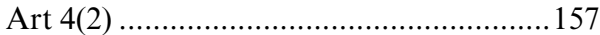

Art 4(3) ...................................... 147, 157

Art 4(4) …................................... 158, 159

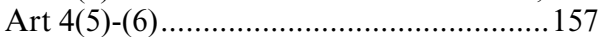

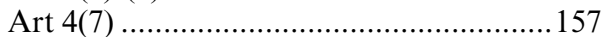

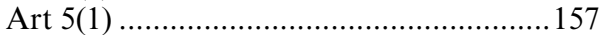

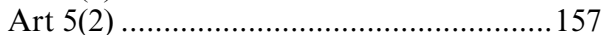

Art 5(3) ................................................. 159

Art 5(6) ..................................... 157, 158

Art 5(7) .................................... 157, 158

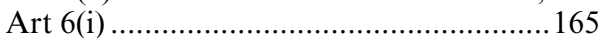

Art 6(1) ................................................. 157

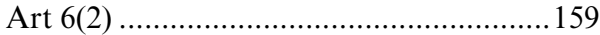

Art 6(5) .................................................... 158

Art 6(6) ............................................... 157

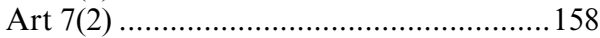

Art 7(3) ................................................. 158

Art 7(4) ............................................... 158

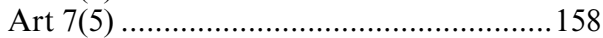

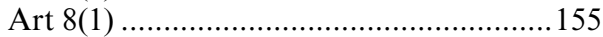

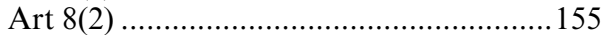

Art 8(4) ............................................. 155

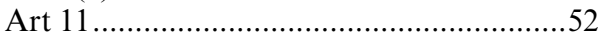

Art 11(1)-(2) ......................................... 155

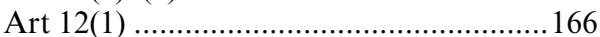

Art 13(1) ...................................... 159, 163

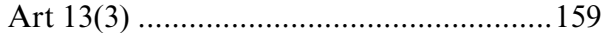

Art 13(4) ............................................. 160

Art 13(7) .............................................. 160

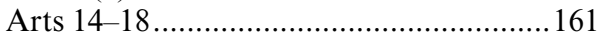

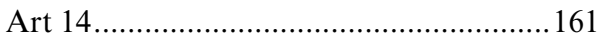

Art 14(6) ................................................ 159

Art 15........................................ 156, 162

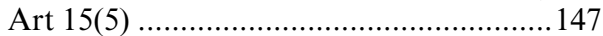

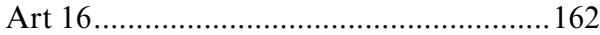

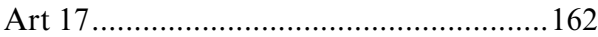

Art 18_.................................................. 162

Art 18(2) ........................................... 159

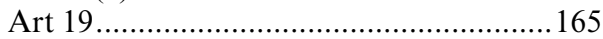




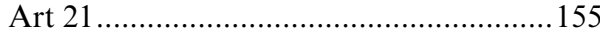

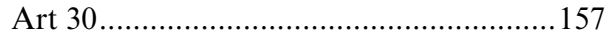

Art 31(1) ............................................. 154

Art 32(2) ................................................. 166

Art 37...................................... 158, 159

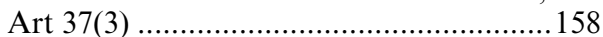

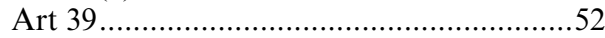

Art 44.................................................... 154

European Stability Mechanism (ESM)

Guideline on Precautionary

Financial Assistance

Art 1

162

Art 2

162,168

Art 2(1) ............................................ 162

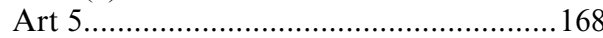

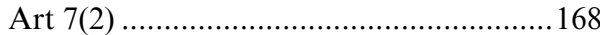

European Stability Mechanism (ESM)

Guideline on Loans

Art 1 162

Art 2(3)(a)

166

European Stability Mechanism (ESM) Guideline on the Primary Market Support Facility

Art 1

European Stability Mechanism (ESM) Guideline on the Secondary Market Support Facility

Art 1

European Stability Mechanism (ESM) Indirect Recapitalization Guideline (Guideline on Financial Assistance for the Recapitalization of Financial Institutions)

Art 1(2) 163,166

Art 1(3)

Art 1(4) $162,163,166,168$

Art 2(2) 163,166

Art 3 163

Art 3(1) 163

Art 3(2) 163

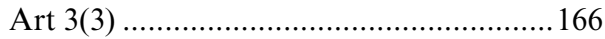

Art 4(4) ................................................ 166

Art 5(a) .............................................. 166

Art 5(1) .................................................. 166

Geneva Securities Convention

(UNIDROIT Convention on

Substantive Rules for Intermediated

Securities, 2009).....................................375

Art 10(2)(b) ..........................................375

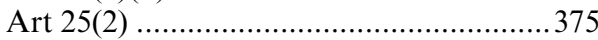

Art 25(6) ................................................ 375

Hague Securities Convention (Convention of 5 July 2006 on the Law Applicable

to Certain Rights in Respect of

Securities held with an Intermediary)

Art 8 ...... 375

International Swap Dealers Association Master Agreement (ISDA)

s 2(c) .332

OECD Principles of Corporate

Governance 309

Statute of the European System of Central Banks and the European Central Bank

Art 6(2) 161

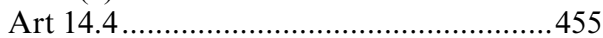

Art 23 ........................................ 161

Art 33.2 ....................................................49

Treaty on Stability, Coordination and Governance (TSCG), 2012 .................. 161

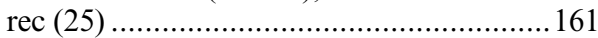

Art 3(1)(a)-(b) ........................................ 161

Art 3(1)(e) ............................................. 161

Art 3(2) .................................................. 161

UNCITRAL Model Law on Cross-

Border Insolvency ................................435

UNIDROIT Principles ...................... 333, 338

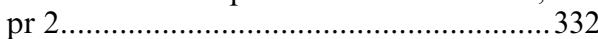

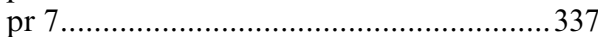

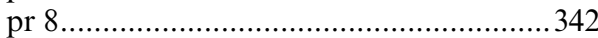

